\title{
Management Information System of Early Warning for Dump Landslide in Opencast Mines
}

\author{
Zhen-Hua Xie ${ }^{1, a}$, Ran-Yi Xie ${ }^{2, b}$, Xiao-Yue Lu ${ }^{1, c}$ \\ ${ }^{1}$ Department of Safety Engineering, China Institute of Industrial Relations, Beijing 100048, China \\ ${ }^{2}$ Civil and Environment Engineering School, University of Science and Technology Beijing, \\ Beijing100083, China \\ axie0015@sina.com, b921981404@qq.com, ${ }^{c} 362169099 @ q q . c o m$
}

Keywords: Dump, Landslide, Extension theory, Management information system of early warning.

\begin{abstract}
As one of the major disasters of opencast mines, landslides not only directly affect mine production safety and economic benefits, but also cause a lot of casualties and property losses. Through analyzing and evaluating the dump landslide danger and the main influencing factors, we proposed the early warning indicator system of dump landslide in opencast mines, established landslide warning system based on the extension theory. By using VB6.0 and Microsoft Access, this early warning management system is developed, this system consists of five modules, including user management, data management, case management, alert management and emergency management, which can realize monitoring data analysis, early warning level determining, accident emergency disposal, and so on,also can provide informationized and intelligentized safety management platform for the enterprises.
\end{abstract}

\section{Introduction}

As a place to receive waste rock sites, the opencast mines dump is an indispensable permanent construction in the production of opencast mines. The phenomenons of dump in China, such as large capacity, high stacking height, lack of attention to the foundation, casual mining and digging at the bottom of slopeseriously,bring potential problemsto the dump stability, leading to increasingly prominentdump landslide hazards. Especially in recent years, mining dump caused landslides and other major disasters, resulted in a large number of casualties and property losses, which raised widespread concern in society. The main problems of dump safety in our country arenon-standard designs, few setting up of safety monitoring facilities, safety early warning and control technology lagging behind.

At present, in terms of the dump disasters research field, there are no patented technology of mine dump early warning, and very few foreign patents focused on the monitoring system equipments. At home and abroad, researches for opencast mine dump disaster warning systems are relatively less, and there is no unified standardsand scientific methods of disaster early warning for the opencast mine. The research of early warning system is also in its infancy, which is lack of informationized, intelligentized and scientizeddisaster early warning management system of dump in opencast mines.

According to different predictionpurposes, landslide prediction is divided into the space prediction and time prediction. Space prediction methodshas fuzzy clustering analysis method, information statistics forecast method, impact factors comprehensive mapping method, sliding distance forecast method, and so on. Time prediction is divided into temporary, short-term and long-term prediction. Long-term prediction methods have fuzzy comprehensive evaluation method by Wang nianqin, experience judgment method by some scholars and so on. Temporary short-term forecasting methods mainly have the time series regression analysis model, wireless telemetry warning system by Wang gongxian, grey forecast modelby Mei rongsheng and so on. In our country, the GIS technology has been used in landslide prediction research in recent years, the monitoring and early warning system have the trend of development to the web-GIS ${ }^{[1]}$. 


\section{Early warning system of dump landslide based on the theory of the extension}

Mine landslide is usually a result of the combined action of the inner and outer factors ${ }^{[2-4]}$, the short-term early warning indicators of mine dump landslide have complex links, sometimes often appear contradictory phenomenons, which makes the study of dump landslide early warning have the complex and dynamic characteristics. The extension theory is a kind of new method which can handle contradictions between incompatible problemsefficiently, whose matter-element model can well fitting complex, dynamic systems like dump landslide.Compared with other analysis methods, the calculation is more simple and efficient.On the basis of the extension theory, the short-term early warning model of dump landslide is established.

Research for early warning indicator system of opencast mine dump landslide. Early warning indicator system is the key to dump landslide early warning, the appropriateness of the selected indicators related to the accuracy of dump landslide early warning result. Selecting early warning methods applicable to the dump landslide is critical. Short-term early warning indicators of dump landslide include displacement, slope height, daily rainfall and monthly cumulative rainfall. For the features of short-term early warning, the choices of the model should focus in as simple methods with easy calculation as possible, which could make the mine companies determine the early warning levels of dump landslide quickly, easily and accurately.

Setting up the indicators of indicator system should be a kind of dynamic analysis and monitoring, on the basis of analysis of past and grasping the future development trend ${ }^{[5]}$. The determination of indicator system is generally divided into two methods,empirical determination method mathematical method. Currently, empirical determination method is used widely ${ }^{[6]}$, while the Delphi method is a common method ${ }^{[7]}$. According to the actual situation of dump landslide, when establishing dump landslide early warning indicator system, consideringthe time of early warning, the indicator system is divided into two parts, short-term and long-term ${ }^{[8]}$, while theshort-term early warning system based on the theory of extension ismainly discussed in this paper.

Construction of dump landslide early warning indicator system is the core content of dump landslide early warning management, the ultimate goal of dump landslide early warning is to eliminate or reduce the dump landslide accidents and hazards, and realize the intrinsic safety. Through monitoring and calculation of the indicators, evaluation and prediction of the current security situation of the enterprise, The enterprise is enable to understand the risks faced by and take effective measures to eliminate hazards and prevent accidents.

The occurrence medium of opencast mine dump is rock, and is closely related to the natural conditions. In considering the early warning indicators, it must be taken into account both its own geological engineering factors and the impact of the external conditions it's being. Considering the actual situation of dump, as shown in Figure 1, the early warning indicator system includes two first grade indicators and four secondary grade indicators. four secondary grade indicators are slope height, displacement, daily rainfall and monthly cumulative rainfall.

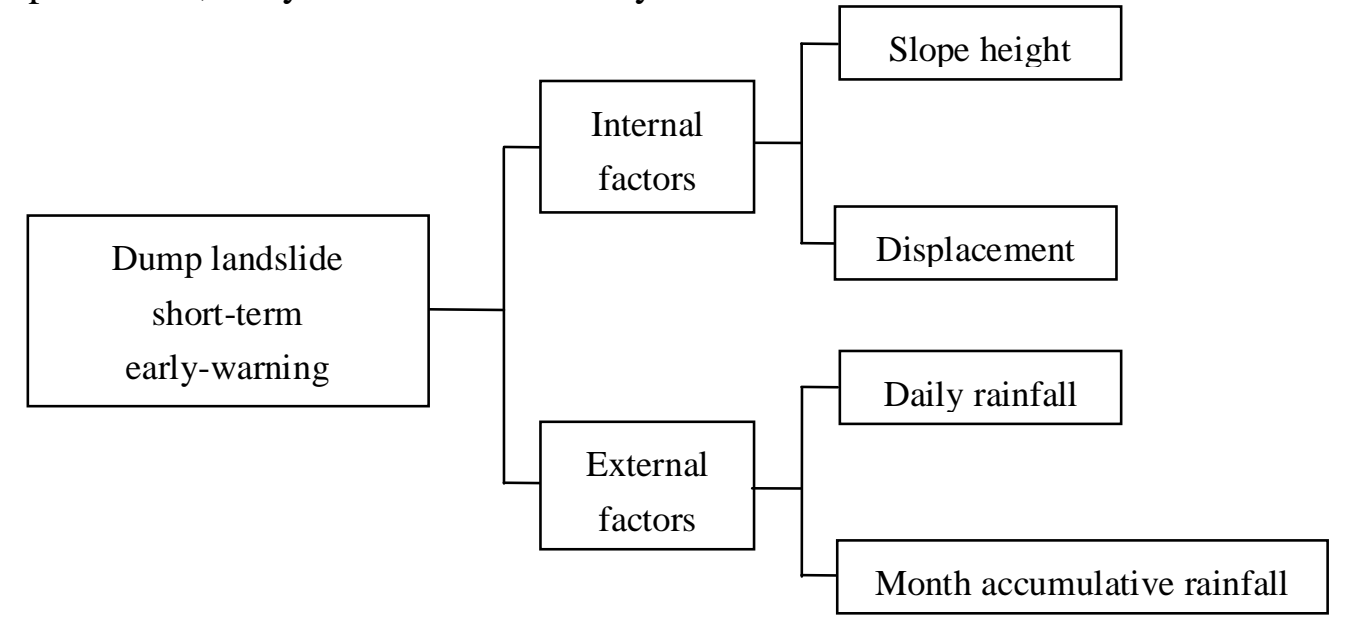

Fig. 1 Dump landslide short-term early-warning indicators system 
Establishment of the landslide early warning model based on the extension theory. The matter-element is the unique concept of extenics, which gives attention to both quality and quantity two aspects at the same time when dealing with problems. It's used to reflect the changes of things through the transformation of matter-element, and describe the changes by formalized languages, resulted in convenient reasoning and computing ${ }^{[9]}$. The extensional evaluation is a method of evaluation which is established on the basis of the matter-element model and extension set theory. It is the combination of qualitative analysis and quantitative calculation, specifically the qualitative analysis through the extensibility of matter-element and the quantitative calculation by the correlation function in extension set theory ${ }^{[10]}$.

The basic principle of the application of the extension theory to the dump landslide early warning is that, establish the extension matter-element model according to dump landslide short-term early warning indicators and the corresponding early warning criteria and grades, and then select the appropriate correlation functionfor the calculation of the relevancy degree of early warning indicators to early warning grades, the greater the relevancy degree is, the better the coincidence degree will be, the grade which the set with largest relevancy degree belongs to is the early warning grade of dump landslide.Early warning flowchartbased on the extension theory is shown in figure 2 .

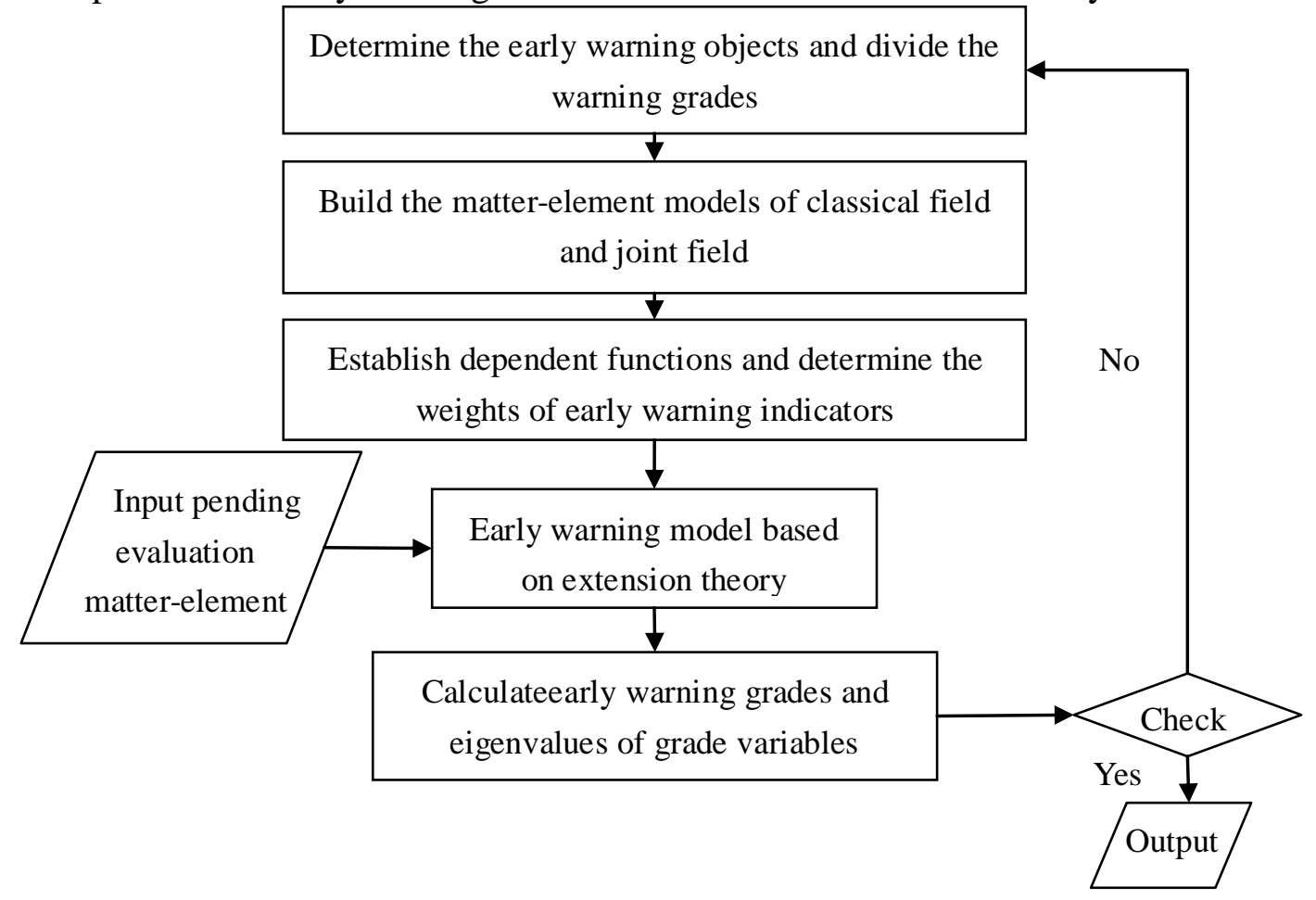

Fig. 2 Early warning flowchart based on the extension theory

\section{The design of the dump landslide early warning management information system}

As shown in figure 3, on the basis of the research approach of dump landslide early warning method, combined with the reality, design the dump landslide early warning management information system according to thoughts of software system engineering.The early warning management system mainly consists of five modules, which are user management, data management, case management, early warning and emergency management respectively, the five modulesare mutually reinforcing and forming a complete system of early warning management.

User management module is the foundation of the system modules, and is the realization of the daily maintenance of the system. It includes the user information addition, user password modification and user information query the three sub-modules; Only added users can operate system, generally, added users are safety production managers of mining enterprises.

Data management module is the guarantee of system modules, which ensures the data security of the system, including data information query, database backup and database recovery the three 
sub-modules; Data information query can facilitate managers to grasp the dynamic data, the database backup, and restore functions can realize regular system database backup, to ensure the security of system data.

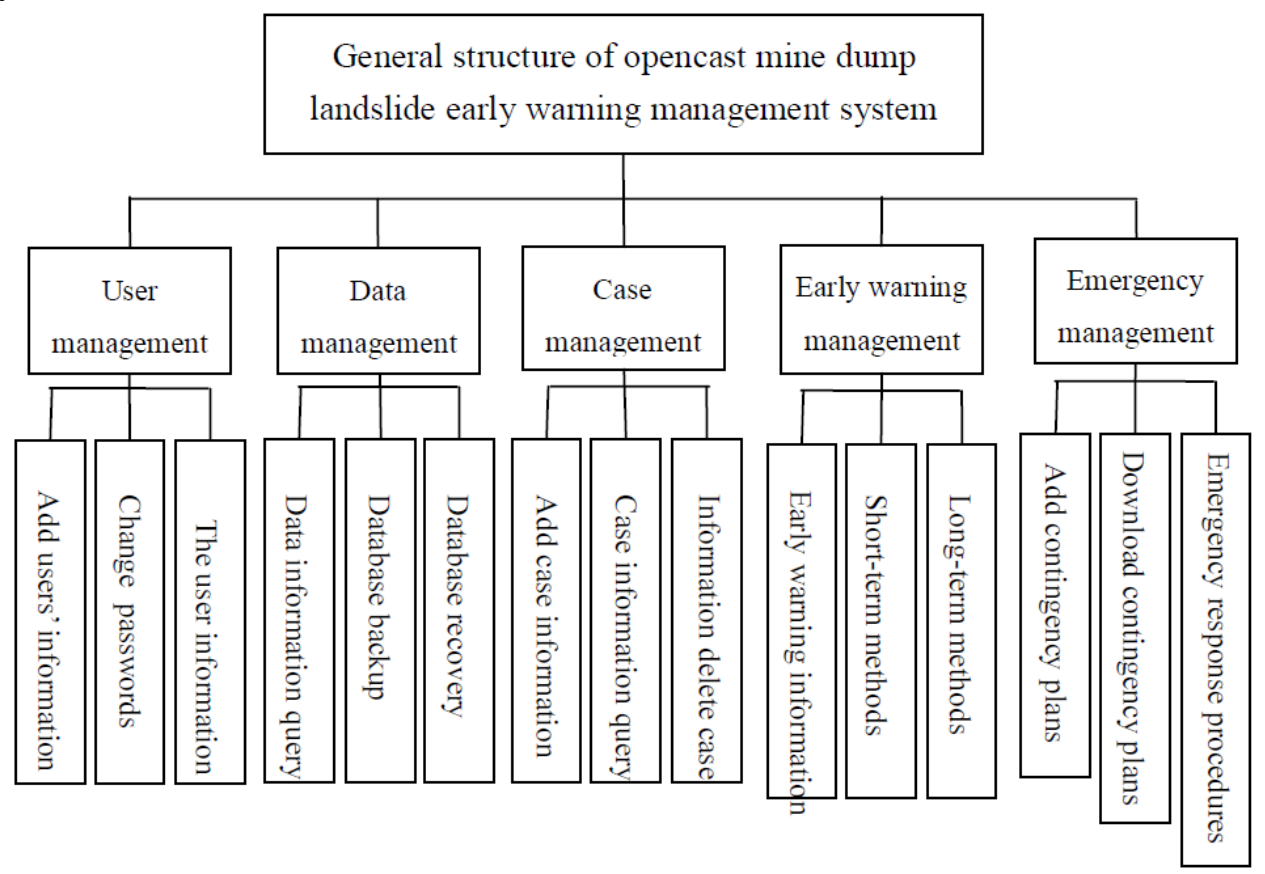

Fig. 3 General structure of opencast mine dump landslide early warning management system

The case management module is the data base of Long-term warning module, at the same time, provide similar cases and disposal measures for long-term warning system, including case information addition, case information query and case information delete the three sub-modules; The information in case base needs to be constantly updating and improving to guarantee the feasibility and validity of the dump landslide early warning based on the case-based reasoning method.

Early warning management module is the core module in the early warning system, which achieves the early warning function of the system. It includes three sub-modules, respectively early warning information query, short-term methods and long-term methods; early warning information query includes the query of the early warning indicator system, the query of early warning indicators' weight, and the query of the early warning grades and criteria, all the early warning information is the basis of the calculation of early warning methods; the short-term early warning method is applying the established extension warning model of dump landslide to calculate the early warning grades.

Emergency management is a supplement to the early warning system module, reflecting the early warning management system's integrity. It includes adding contingency plans, download contingency plans and emergency response procedures the three sub-modules; According to the warning, referring to the corresponding contingency plans, it provides the basis for the enterprise emergency management, emergency response program provides emergency rescue process after receiving accident alarm.

\section{The function realization of the dump landslide early warning management system}

According to the result of comparative analysis, the C/S mode has obvious advantages in development of early warning management information management system. Visual Basic 6.0 (VB6.0 by use) has characteristics of easy to master, visualization, simple and efficient operation, therefore, VB6.0 is chose to be software development language for dump landslide early warning management system. The main functions of Microsoft Office Access includes information retrieval query, data storage and good graphical interface. The data quantity and scale of current opencast 
mine landslide early warning management system have not reached the requirements of a large database, so Microsoft Office Access is chose to establish database.

Main interface. When using this system, before loginingto main interface ofsystem, usersenter the user name and password, click ok to enter the main interface of system, as shown in figure 4. The main interface of the early warning management system displays six menu functions.

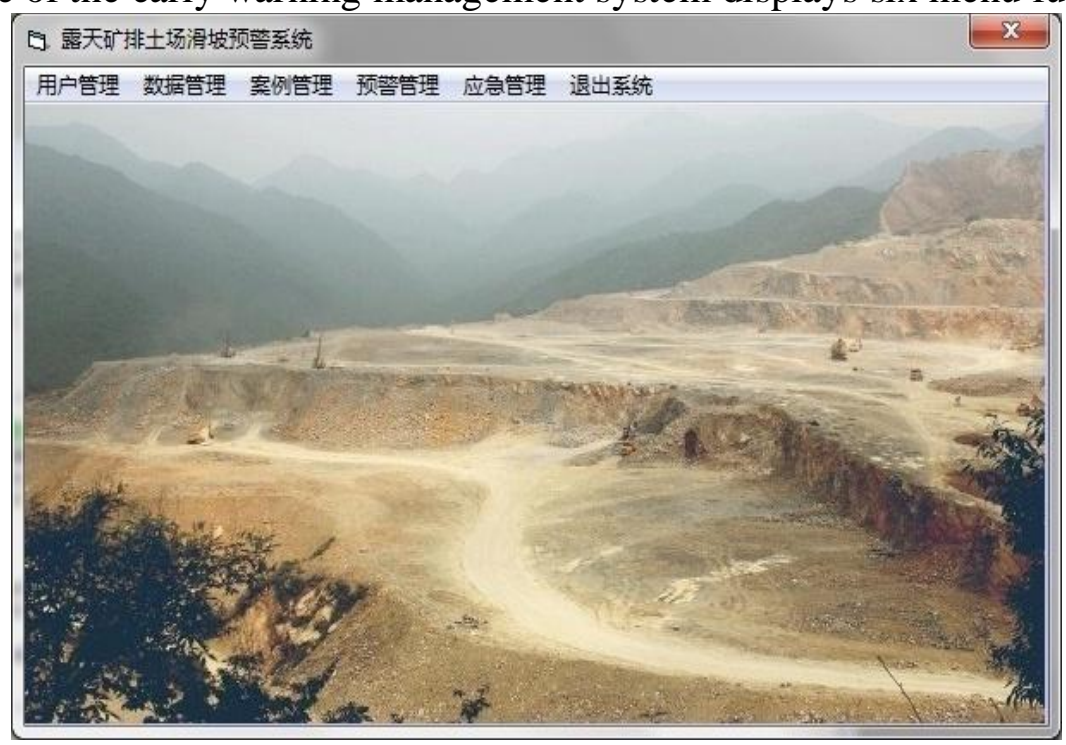

Fig. 4 The system main interface

Early warning management. Early warning management modules include early warning information query, short-term methods and long-term methods three sub-modules. This part is the core of early warning management, including much information and complex function realization, and the basic idea is implemented according to the established short-term early warning indicator system in this paper, the determined weight and the study of early warning methods.

Early warning management module is the core module in the early warning system, which achieves the early warning function of the system. It includes three sub-modules, respectively early warning information query, short-term methods and long-term methods; early warning information query includes the query of the early warning indicator system, the query of early warning indicators' weight, and the query of the early warning grades and criteria, all the early warning information is the basis of the calculation of early warning methods; the short-term early warning method is applying the established extension warning model of dump landslide to calculate the early warning grades.

Short-term early warning information query includes short-term early warning indicator system and weight, short-term early warning criteria, and so on. Early warning criteria are divided into five grades, respectively level I, II, III, IV and V. Choose one warning grade, the corresponding different colors will display in the early warning signals, level I corresponding to red alert, level II corresponding to orange alert, level III corresponding to yellow alert, level IV corresponding to blue alert, level $\mathrm{V}$ corresponding to no alert. When the early warning signal is green, under the early warning criteria, it will show the value ranges and score ranges of eight early warning indicators, as shown in figure 5.

Short-term warning methods are based on the elements of extenics. The first is calculation elements of the methods, the user only needs to input four short-term early warning indicators' monitoring data values, click input, depending on the values of early warning data to be entered, the system will calculate the comprehensive correlation degree of the early warning indicators to early warning grades. According to the values of maximum correlation degree and grade characteristic variables, judge the early warning grade and name of early warning data. As shown in figure 6 . 

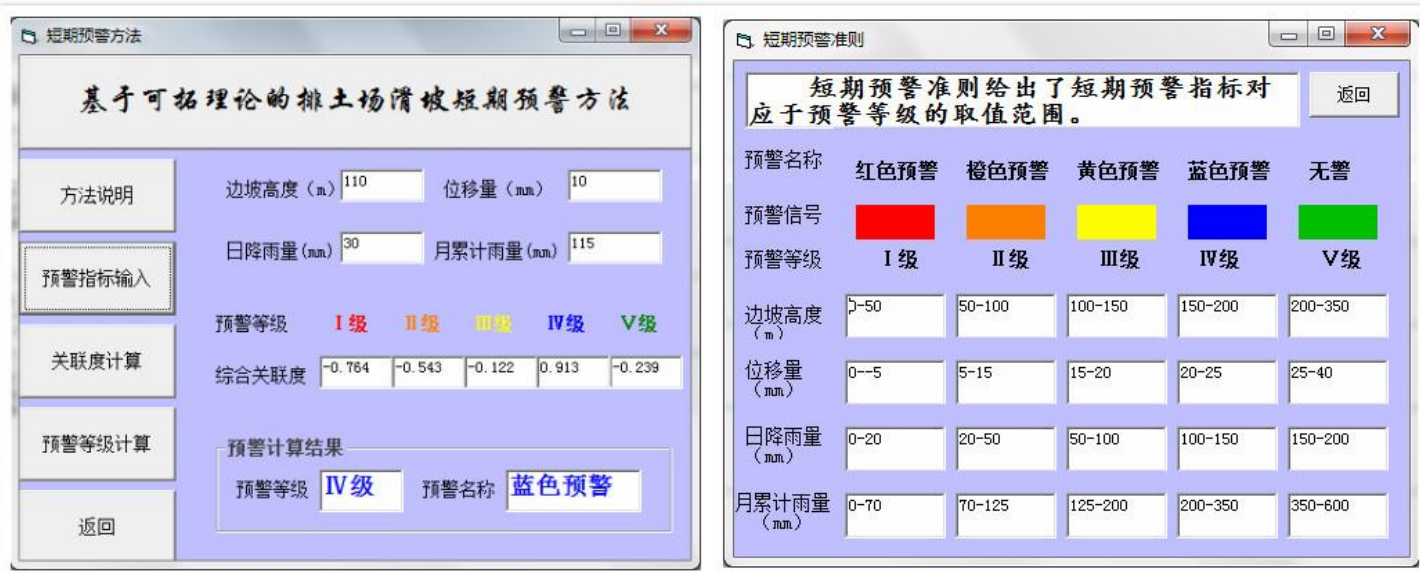

Fig. 5 Short-term early warning criteria Fig. 6 Short-term early warning methods

\section{Conclusion}

1) Considering the factors of landslide and practical situation, establish opencast mine dump landslide short-term early-warning indicator system, including the slope height, displacement, daily rainfall and month accumulative rainfall the four indicators.

2)Adopting the method of extenics to proceed the dump landslide short-term early warning can well fit the complex dynamic systems likedump landslide. By using the matter-element model and correlation function, combined with the early warning criteria and weight values of short-term early warning indicators, dump landslide short-term early warning model is established based on the extension theory.

3) Appling Visual Basic language and Access database to develop the opencast mine dump landslide early warning management system in $\mathrm{C} / \mathrm{S}$ mode, the system achieved the entry and query of information, backup and restore functions of the database, mainly achieved the long-term and short-term early warning functions of the dump landslide, and provide intelligentized, informationized and scientized management platform for the enterprises' safety production.

\section{Acknowledgment}

The research is the phase achievement of the college scientific research"Study on the method of the disaster early warning in opencast mine " projectsupported by China Institute of Industrial Relations (project No. 15YY001).

\section{References}

[1] Yaming TANG, Maoxing ZHANG, et al. Landslide monitoring and early-warning:an overview, Geological Review. 58.3 (2012): 533-541.

[2] Jun WANG,YijunWANG, XuebaoFAN. Analysis on stability of refuse dump for rail in open-pit mine,Steel Science and Technology. 3 (2010): 7-10.

[3] Peng CHEN, Pengfei CHEN. Slope stability analysis on waste disposal site of opencast,Jounal of Liaoning Technical University Natural Science.29.6 (2011): 1028-1031.

[4] YunminWANG, Honghai XIANG. Dumping stability and disaster prevention, Metallurgical Industry Press Beijing, 2011.

[5] Xiaojuan HUANG, Beilin LIU.Warning index system for food security,Journal of Harbin University of Commerce(Natural Science).24.5 (2008): 621-623.

[6] Yingwang XIAO. Dynamic latent variable method and its application in dynamic process monitoring, Chinese Journal of Scientific Instrument.33.1 (2012): 113-119. 
[7] Aijun YAN, Limin QIAN, Pu WANG.A Comparative Study of Attribute Weights Assignment for Case-based Reasoning,ACTA Automatica Sinica.40.9 (2014): 1896-1902.

[8] Pingxin WEI, Senlin YANG.Realization and significance of early-warning of geo-hazard in short-time meteorology in Guangdong, Journal of Geological Hazards and Environment Preservation.22.2 (2011): 54-59.

[9] Heng LIU. The slope stability assessment based on the theory of extenics. Beijing Jiaotong University of Science Master Degree Thesis, 2009.

[10] Yichen ZHANG, et al.The 5rd Annual Meeting of RAC, 2012. 